\title{
CARACTERIZAÇÃO E AVALIAÇÃO DA INFLUÊNCIA DAS PROPRIEDADES FÍSICO-QUÍMICAS SOBRE A INCIDÊNCIA DE STAPHYLOCOCCUS AUREUS EM HAMBÚRGUER DE CARNE BOVINA PRODUZIDO EM UM FRIGORÍFICO LOCALIZADO NO MUNICÍPIO DE CAMPO GRANDE/MS
}

\author{
A. STAUDT $^{1}$, W. DA S. ROBAZZA ${ }^{2}$ \\ ${ }^{1}$ Universidade Regional Integrada do Alto Uruguai e das Missões \\ ${ }^{2}$ Universidade do Estado de Santa Catarina, Departamento de Engenharia de Alimentos e Engenharia \\ Química \\ E-mail para contato: amanda_staudt@hotmail.com
}

\begin{abstract}
RESUMO - Bactérias da espécie Staphylococcus aureus são um importante veículo de Doenças Transmitidas por Alimentos (DTAs). Este micro-organismo é amplamente encontrado em alimentos à base de carne bovina, como hambúrgueres. Neste contexto, o presente estudo tem como objetivo estimar a influência dos teores de cinza, proteína, umidade, gordura, cálcio e carboidratos no desenvolvimento de Staphylococcus aureus em hambúrguer de carne bovina. Utilizou-se uma amostragem de 69 lotes de hambúrgueres de carne bovina produzidos em indústria de alimentos localizada em Campo Grande, MS, Brasil. Os resultados obtidos mostraram que os parâmetros físicoquímicos avaliados não apresentam correlação com o crescimento de $S$. aureus em hambúrguer de carne bovina. Vê-se como importante a elaboração de outros estudos com o objetivo de determinar os fatores que influenciam o crescimento desta bactéria em produtos cárneos.
\end{abstract}

Palavras-chave: Staphylococcus aureus, hambúrguer, produtos cárneos, parâmetros físico-químicos

DOI: $10.5965 / 24473650312017010$

\section{INTRODUÇÃO}

Bactérias do gênero Staphylococcus são apresentadas na forma de cocos Gram-positivos, pertencentes à família Micrococcaceae. São bactérias mesófilas, anaeróbias facultativas e não esporuladas. A espécie Staphylococcus aureus causa intoxicação decorrente da ingestão de alimentos que apresentam a toxina pré-formada, sendo esta termoestável, podendo permanecer viável mesmo após a cocção dos alimentos. (FRANCO, LANDGRAF, 1996; PARDI et al., 2001; SILVA, GRANDA, 2004; CUNHA NETO, SILVA, STAMFORD, 2002).

Sintomas como náuseas, vômito, cãibras abdominais, diarreia e sudorese aparecem cerca de trinta minutos a oito horas após a ingestão do alimento contaminado. O tempo de incubação e os 
sintomas variam com o grau de suscetibilidade do indivíduo, concentração de enterotoxina presente no alimento e quantidade ingerida. (FRANCO, LANDGRAF, 1996).

O principal reservatório para bactérias do gênero estafilococos é o ser humano. Estes organismos são encontrados na pele, cabelos, garganta e mucosas da membrana da nasofaringe e são abundantes em cortes, pústulas e abcessos (BRYAN, 1978,1980; BERGDOLL, 1990). Aproximadamente $50 \%$ da população humana é portadora de Staphylococcus aureus, sendo que, manipuladores com lesões na pele, ao tossir ou espirrar, podem contaminar diretamente o alimento por bactérias desse gênero (GUNDOGAN et al., 2005).

O desenvolvimento microbiano em alimentos depende de diversos fatores. Entre esses fatores encontram-se aqueles relacionados com as características próprias do alimento, denominados fatores intrínsecos, e também aqueles inerentes ao ambiente em que o produto se encontra, denominados fatores extrínsecos. São considerados fatores intrínsecos a atividade de água, a acidez, o potencial de oxi-redução, a composição química, a presença de fatores antimicrobianos naturais e as interações entre micro-organismos. Por sua vez, os fatores extrínsecos são compreendidos pela umidade e a temperatura ambiental (FRANCO, LANDGRAF, 1996; HOFFMAN, 2001; SILVA, 2012).

Staphylococcus aureus pode ser transmitida por diferentes alimentos, incluindo leite, sorvete, atum, presunto, frango e carne (FRANCO, LANDGRAF, 1996; ÇITAK, VARLIK; GÜNDOǦAN, 2003; KANBAKAN, ÇON, AYAR, 2004; SCHLEGELOVA et al., 2004).

De acordo com Gundogan et al., (2005), Staphylococcus aureus é a mais importante espécie de Staphylococcus causadora de doenças transmitidas por alimentos. Sobre os surtos de origem alimentar, aproximadamente $48 \%$ do total observado no México, $66 \%$ na Inglaterra e País de Gales (PARRILLA-CERRILO et al., 1993), 86\% no Egito (FAWZY, 1999) são atribuídos a Staphylococcus aureus. Além destes, recentemente foram observados surtos de intoxicação alimentar com Staphylococcus no Japão (SUZUKI et al., 2017), na Escócia (ELDIRDIRI et al., 2017) e na África do Sul (DRAMOWSKI et al., 2017).

Segundo a Instrução Normativa $n^{\circ} 20$ de 31 de julho de 2000, entende-se por hambúrguer o produto cárneo industrializado obtido da carne moída dos animais de açougue, adicionado ou não de tecido adiposo e ingredientes, moldado e submetido a processo tecnológico adequado (BRASIL, 2000).

A necessidade de refeições fora de casa que sejam rápidas e baratas fez com que se expandisse o mercado para hambúrgueres de carne bovina. De acordo com Queiroz et al., (2005) o hambúrguer integra a rotina alimentar da população brasileira, em consequência de suas características sensoriais, facilidade de preparo e ressaltado teor de proteínas, lipídios, vitaminas e minerais.

Frente ao grande consumo de hambúrgueres de carne bovina e por este ser um potencial veículo de contaminação por Staphylococcus aureus, este estudo tem como objetivo determinar a influência dos teores de cinza, proteína, umidade, gordura, cálcio e carboidratos no desenvolvimento de Staphylococcus aureus em hambúrguer de carne bovina.

\section{MATERIAIS E MÉTODOS}

O trabalho foi realizado a partir de dados coletados em uma indústria de alimentos processadora de carne bovina localizada no município de Campo Grande/MS, Brasil. A 
amostragem foi de 69 lotes de hambúrguer de carne bovina. As análises dos teores de cinza, proteína, umidade, gordura, cálcio, carboidrato e contagem de Staphylococcus aureus foram realizadas em laboratório credenciado e comumente utilizado pela empresa.

As metodologias utilizadas nas análises são (1) cinzas - Determinação de cinzas - IAL; (2) proteína - Determinação de Nitrogênio - Princípio de Dumas (LECO); (3) umidade Determinação de Umidade - Referência AOAC; (4) gordura - Determinação de Lipídios (Extração); (5) cálcio - Determinação de Cálcio (Método por EDTA); (6) carboidratos Determinação de Carboidratos - IAL; (7) Staphylococcus aureus - Enumeração de Staphylococcus aureus pelo Método Alternativo Petrifilm.

Todas as análises estatísticas foram realizadas com o software R v. 3.2.2 for Windows.

\section{RESULTADOS E DISCUSSÃO}

\subsection{Incidência de $S$. aureus}

Foi observada a presença de $S$. aureus em 7,24\% das amostras de hambúrguer analisadas, com contagem variando entre 1,00 e 2,11 log UFC/g. Ranucci et al. (2004) isolaram S. aureus em $21,1 \%$ das amostras de hambúrguer e rissole de carne, enquanto Aycicek, Cakiroglu e Stevenson (2005) detectaram $S$. aureus em $13,6 \%, 7,0 \%$ e 6,4\% de três lotes de amostras de hambúrguer analisadas. Hanashiro et al., (2005) em estudo sobre a qualidade microbiológica de alimentos comercializados em ruas de determinada área de São Paulo, perceberam que, a partir de 40 amostras de alimentos não processados industrialmente, somente uma apresentou resultado positivo para o crescimento de $S$. aureus, sugerindo que a contaminação destes alimentos após o cozimento era incomum.

Observa-se que as contagens obtidas apresentam-se dentro dos padrões descritos pela RDC $\mathrm{n}^{\circ} 12$, de 02 de janeiro de 2001, para produtos cárneos congelados de no máximo 3,70 log UFC/g (Brasil, 2001). Estas contagens também satisfazem as normas dos Estados Unidos, as quais estabelecem que, amostras contendo entre 2 e $3 \log$ UFC/g são marginalmente aceitáveis (Center for Food Safety \& Applied Nutrition, 1992).

Shahraz et al., (2012) enfatizam que a alta porcentagem de contaminação por $S$. aureus em amostras de hambúrguer representa um risco para a saúde do consumidor e salienta a importância de mais atenção frente às boas práticas de higiene com o objetivo de diminuir os níveis de contaminação na carne e subprodutos industriais.

\subsection{Avaliação dos Parâmetros Físico-Químicos}

A empresa fornecedora das amostras apresenta rigoroso controle de qualidade sobre seus produtos. Boa parte da matéria-prima utilizada na produção dos hambúrgueres é proveniente da própria empresa, com isso, consegue-se uma matéria-prima de maior qualidade, tendo em vista que a empresa conta com exigentes programas de Boas Práticas de Fabricação (BPF) e de Análise de Perigos e Pontos Críticos de Controle (HACCP). O ponto crítico de controle mais importante frente à contaminação microbiana encontra-se na etapa de toalete da carcaça, onde se faz o controle da presença de fezes, pelo e ingesta, e sua remoção. 
Frente a isso, percebe-se que a contaminação por $S$. aureus ocorre durante a industrialização do produto. Shahraz et al. (2012) comentam que é de grande importância determinar a influência dos diversos fatores frente a contaminação por $S$. aureus. Dentre esses fatores encontram-se a composição do hambúrguer (proteínas, água, lipídios) e condições de armazenamento.

A Figura 1 apresenta os valores obtidos para os teores de cinzas (Fig. 1a), proteína (Fig. 1b), umidade (Fig. 1c), gordura (Fig. 1d), cálcio (Fig. 1e) e carboidrato (Fig. 1f) e sua ocorrência nas 69 amostras analisadas.

Percebe-se que a maioria das amostras apresenta teor de cinzas entre 0,5 e 1,0\% (fig. 1a). Estes valores se encontram próximos aos encontrados por Santos Junior et al., (2009), que obtiveram teor de cinzas médio de $1,18 \%$ para hambúrguer de carne de ovinos enriquecido com farinha de aveia.

Quanto ao teor de proteína (fig. 1b), a maior parte das amostras apresentam valores entre 16 e 18\%. A maioria das amostras se encontra de acordo com a Instrução Normativa $n^{\circ} 20$ de 31 de julho de 2000, que determina teor de proteínas mínimo para hambúrguer de $15 \%$. Para a porcentagem de gordura (fig. 1d), todas se encontram de acordo com a legislação vigente que determina teor de gordura máximo de 23\% (BRASIL, 2001).

Para o teor de umidade (fig. 1c), a maioria dos hambúrgueres analisados apresentou teores superiores a 59\%. Estes valores concordam com o valor médio obtido por Borba (2010), que obteve teor de umidade de 60,29\% para hambúrguer de carne bovina.

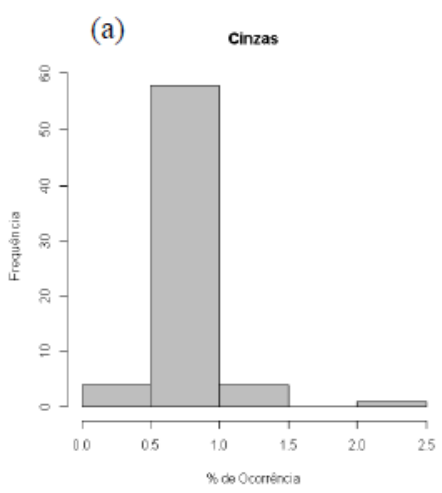

(d)

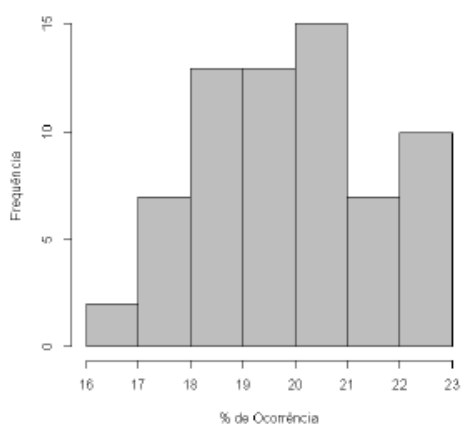

(b)

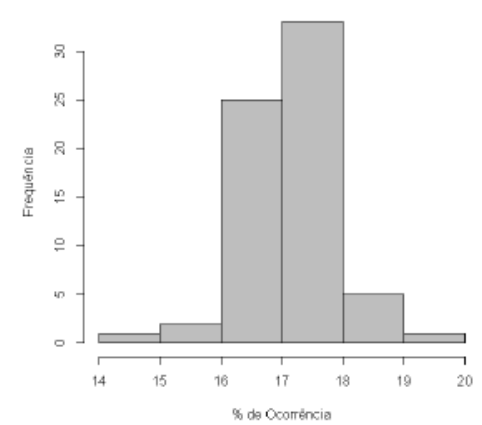

(e)

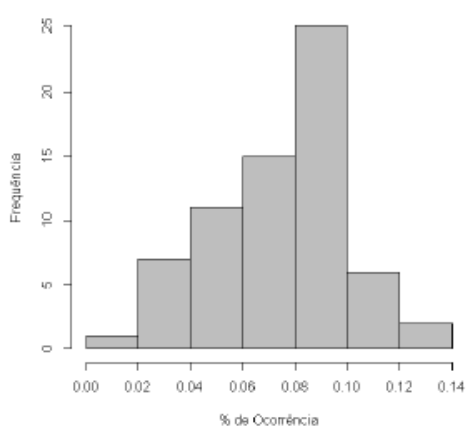

(c)

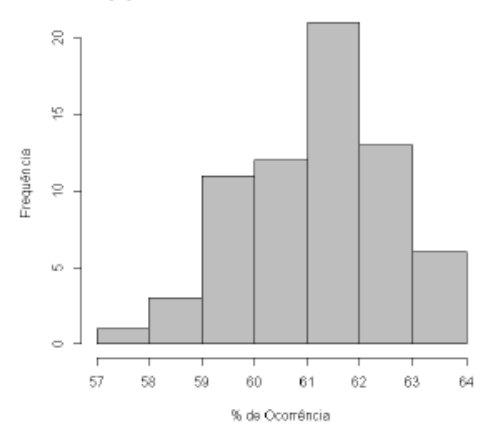

(f)

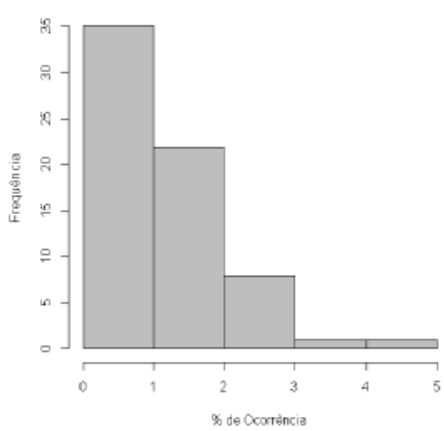

Figura 1 - Histograma relativo à presença de (a) cinzas; (b) proteínas; (c) umidade; (d) gordura; (e) cálcio; (f) carboidrato nas amostras analisadas 
A Instrução Normativa $n^{\circ} 20$, de 31 de julho de 2000, determina teor de cálcio máximo de $0,1 \%$ para hambúrguer. A maioria das amostras analisadas se encontra dentro dos padrões, porém, cinco amostras foram reprovadas quanto ao teor de cálcio (fig. 1e). Segundo esta mesma legislação, o teor de carboidratos totais deve ser igual a 3\%, tendo em vista que a maioria das amostras apresentou teor de carboidratos até 3\% (fig. 1f), logo é possível se considerar que as amostras estão em conformidade com a legislação (BRASIL, 2001).

\subsection{Análises estatísticas}

Nesta etapa, procurou-se avaliar se havia alguma correlação entre os parâmetros físicoquímicos das amostras e a incidência de $S$. aureus nas mesmas.

A Tabela 1 mostra os índices estatísticos relativos a cada um dos parâmetros físicoquímicos apresentados na Figura 1 e também quanto à contagem de Staphylococcus aureus nas amostras analisadas

Tabela 1 - Índices estatísticos relativos à contagem de $S$. aureus e aos parâmetros físico-químicos nas amostras de hambúrguer avaliadas

\begin{tabular}{ccccccc}
\hline & Média & Mediana & Moda & Desvio-Padrão & Amplitude & CV $(\%)$ \\
\hline S. aureus & 2,99 & 0,00 & 0,00 & 16,33 & 130,00 & 547,10 \\
Cinza & 0,83 & 0,80 & 0,80 & 0,25 & 2,00 & 29,85 \\
Proteína & 17,09 & 17,20 & 17,20 & 0,71 & 4,30 & 4,14 \\
Umidade & 61,16 & 61,40 & $61,60-$ & 1,36 & 6,30 & 2,22 \\
& & & $61,70-62,00$ & & & \\
Gordura & 19,84 & 19,80 & 20,00 & 1,65 & 6,30 & 8,33 \\
Cálcio & 0,07 & 0,06 & 0,08 & 0,03 & 0,13 & 39,70 \\
Carboidrato & 1,11 & 0,90 & 0,40 & 0,85 & 4,50 & 76,06 \\
\hline
\end{tabular}

Observa-se pelo valor do desvio-padrão, que os valores para $S$. aureus apresentam grande variação de contagem, já que a maior contagem obtida foi igual a $130 \mathrm{UFC} / g$. Devido ao alto valor de desvio-padrão explica-se a alta taxa de coeficiente de variação $(\mathrm{CV})$, pois, quanto maior o valor do coeficiente de variação, mais dispersos os resultados estão em comparação com a média (WITTE, WITTE, 1997).

Com o objetivo de medir o grau de interdependência numérica entre a contagem de $S$. aureus e os parâmetros físico-químicos desenvolveu-se a Tabela 2, a qual consiste na matriz de covariância entre todos os parâmetros abordados no presente estudo. Cada elemento desta matriz exprime o grau de variabilidade de cada parâmetro e a interdependência entre os parâmetros quando tomados dois a dois (WITTE, WITTE, 1997).

Sabendo-se que variáveis independentes tem covariância igual a zero, observa-se que todas as variáveis estão relacionadas, em menor ou maior escala, com a contagem de $S$. aureus. Pela tabela vê-se que a contagem de $S$. aureus apresenta maior relação com o teor de carboidratos. Por esta razão, desenvolveu-se a Tabela 3, a qual apresenta a matriz de correlação entre os parâmetros, com a intenção de determinar-se de forma quantitativa a correlação entre a contagem de $S$. aureus e os demais parâmetros avaliados. 
Tabela 2 - Matriz de covariância entre os parâmetros avaliados

\begin{tabular}{cccccccc}
\hline & S. aureus & Cinza & Proteína & Umidade & Gordura & Cálcio & Carboidrato \\
\hline S. aureus & 266,7119 & 0,1352 & 0,3594 & 0,2191 & 0,4230 & 0,0416 & $-1,2983$ \\
Cinza & 0,1352 & 0,0607 & 0,0108 & 0,0373 & $-0,0473$ & 0,0015 & $-0,0296$ \\
Proteína & 0,3594 & 0,0108 & 0,5019 & 0,1761 & $-0,3338$ & - & $-0,2223$ \\
& & & & & & 0,0018 & \\
Umidade & 0,2191 & 0,0373 & 0,1761 & 1,8518 & $-2,0048$ & 0,0066 & $-0,1113$ \\
Gordura & 0,4230 & $-0,0473$ & $-0,3338$ & $-2,0048$ & 2,7290 & - & $-0,3238$ \\
& & & & & & 0,0090 & \\
Cálcio & 0,0416 & 0,0015 & $-0,0018$ & 0,0066 & $-0,0090$ & 0,0007 & 0,0041 \\
Carboidrato & $-1,2983$ & $-0,0296$ & $-0,2223$ & $-0,1113$ & $-0,3238$ & 0,0041 & 0,7172 \\
\hline
\end{tabular}

Observa-se, na Tab. 3, que os parâmetros físico-químicos que possuem maior correlação com a contagem de $S$. aureus são o teor de carboidrato e o teor de cálcio. Conforme estudo realizado por Hunt et al (2012), a presença de carboidratos foi correlacionada positivamente com o crescimento de $S$. aureus em leite. Este fenômeno se deve à utilização dos carboidratos como receptores para a infecção por estas bactérias (KATO, ISHIWA, 2015). Outro estudo comprovou que a presença de Cálcio inibe a formação de biofilmes desta bactéria afetando seu crescimento (ABRAHAM, JEFFERSON, 2012). Nota-se, também, que os parâmetros físico-químicos analisados não apresentam correlação significativa frente ao crescimento de $S$. aureus nas amostras analisadas.

Tabela 3 - Matriz de correlação entre os parâmetros avaliados

\begin{tabular}{cccccccc}
\hline & S. aureus & Cinza & Proteína & Umidade & Gordura & Cálcio & Carboidrato \\
\hline S. aureus & 1,0000 & 0,0336 & 0,0308 & 0,0099 & 0,0183 & 0,0947 & $-0,0939$ \\
Cinza & 0,0336 & 1,0000 & 0,0619 & 0,1113 & $-0,1163$ & 0,2259 & $-0,1418$ \\
Proteína & 0,0308 & 0,0619 & 1,0000 & 0,1826 & $-0,2852$ & $-0,0947$ & $-0,3705$ \\
Umidade & 0,0099 & 0,1113 & 0,1826 & 1,0000 & $-0,8918$ & 0,1806 & $-0,0966$ \\
Gordura & 0,0183 & $-0,1163$ & $-0,2852$ & $-0,8918$ & 1,0000 & $-0,2023$ & $-0,2315$ \\
Cálcio & 0,0947 & 0,2259 & $-0,0947$ & 0,1806 & $-0,2023$ & 1,0000 & 0,1796 \\
Carboidrato & $-0,0939$ & $-0,1418$ & $-0,3705$ & $-0,0966$ & $-0,2315$ & 0,1796 & 1,0000 \\
\hline
\end{tabular}

Finalmente, testou-se a eficiência de 3 modelos matemáticos para testar a influência dos diferentes parâmetros sobre a incidência de $S$. aureus sobre as amostras estudadas. Esses modelos foram desenvolvidos sob o método de minimização dos quadrados. O primeiro levou em consideração todos os 6 parâmetros físico-químicos estudados através de um polinômio de primeiro grau. O segundo levou em conta somente os parâmetros Cálcio e Carboidrato através de um polinômio de segundo grau e o terceiro considerou somente o teor de Cálcio através de um polinômio de terceiro grau. As Equações 1, 2 e 3 indicam os três modelos adotados, respectivamente: 


$$
\begin{gathered}
y=A_{0}+A_{1} x_{1}+A_{2} x_{2}+A_{3} x_{3}+A_{4} x_{4}+A_{5} x_{5}+A_{6} x_{6} \\
y=A_{0}+A_{1} x_{5}+A_{2} x_{6}+A_{3} x_{5}^{2}+A_{4} x_{5} x_{6}+A_{5} x_{6} \\
y=A_{0}+A_{1} x_{5}+A_{2} x_{5}^{2}+A_{3} x_{5}^{3}
\end{gathered}
$$

onde:

$y$ : Contagem de Staphylococcus aureus (UFC/g)

$x_{1}:$ Cinza $(\%)$

$x_{2}$ : Proteína $(\%)$

$x_{3}:$ Umidade $(\%)$

$x_{4}:$ Gordura $(\%)$

$x_{5}:$ Cálcio (\%)

$x_{6}$ : Carboidrato $(\%)$

A Tabela 4 apresenta os valores dos parâmetros, desvios-padrão respectivos e coeficientes de determinação para todos os modelos abordados.

É possível observar-se, a partir dos valores da Tabela 4 que nenhum dos modelos testados gerou bons ajustes dos dados experimentais, tendo em vista os valores baixos dos coeficientes de determinação e os valores elevados dos desvios-padrão dos parâmetros em relação às estimativas. Logo, ficou mais uma vez comprovado que não há correlação significativa entre os parâmetros físicoquímicos e a incidência de $S$. aureus nas amostras estudadas.

Tabela 4 - Matriz de correlação entre os parâmetros avaliados

\begin{tabular}{ccc}
\hline Modelo $1\left(R^{2}=0,0231\right)$ & Estimativa & Desvio-Padrão \\
\hline $\mathrm{A}_{0}$ & 167,0919 & 687,9847 \\
$\mathrm{~A}_{1}$ & $-1,2575$ & 9,4068 \\
$\mathrm{~A}_{2}$ & $-0,9246$ & 5,5606 \\
$\mathrm{~A}_{3}$ & $-1,9270$ & 7,6188 \\
$\mathrm{~A}_{4}$ & $-1,5427$ & 6,9782 \\
$\mathrm{~A}_{5}$ & 76,5044 & 83,6931 \\
$\mathrm{~A}_{6}$ & $-3,5806$ & 6,5007 \\
\hline Modelo $2\left(R^{2}=0,0372\right)$ & Estimativa & Desvio-Padrão \\
\hline $\mathrm{A}_{0}$ & $-4,4162$ & 12,0932 \\
$\mathrm{~A}_{1}$ & 339,8345 & 312,7199 \\
$\mathrm{~A}_{2}$ & $-8,0981$ & 11,9578 \\
$\mathrm{~A}_{3}$ & $-2180,3757$ & 2303,0189 \\
$\mathrm{~A}_{4}$ & 45,7462 & 117,3335 \\
$\mathrm{~A}_{5}$ & 0,6784 & 1,7726 \\
\hline Modelo $3\left(R^{2}=0,0202\right)$ & Estimativa & Desvio-Padrão \\
\hline
\end{tabular}




\begin{tabular}{ccc}
\hline $\mathrm{A}_{0}$ & $-8,719 \times 10^{-1}$ & $2,071 \times 10^{+1}$ \\
$\mathrm{~A}_{1}$ & $-7,670 \times 10^{+1}$ & $9,677 \times 10^{+2}$ \\
$\mathrm{~A}_{2}$ & $3,625 \times 10^{+3}$ & $1,346 \times 10^{+4}$ \\
$\mathrm{~A}_{3}$ & $-2,203 \times 10^{+4}$ & $5,658 \times 10^{+4}$ \\
\hline
\end{tabular}

\section{CONCLUSÕES}

Conclui-se, a partir deste estudo, que os teores de cinza, proteína, umidade, gordura e carboidrato não apresentam correlação significativa quanto ao crescimento de Staphylococcus aureus em hambúrgueres de carne bovina no frigorífico estudado. Como os parâmetros analisados não foram influentes no crescimento dessa bactéria percebe-se que a contaminação dos hambúrgueres com contagem positiva pode ter ocorrido devido a problemas durante o processamento do mesmo ou até mesmo durante a fase de manejo dos animais, a qual não foi abordada durante o presente estudo.

Portanto, mais estudos devem ser realizados com o objetivo de determinar os parâmetros que influenciam o desenvolvimento desta bactéria em produtos cárneos do tipo hambúrguer.

\section{REFERÊNCIAS}

ABRAHAM, N. M.; JEFFERSON, K. K. Staphylococcus aureus clumping factor B mediates biofilm formation in the absence of calcium Microbiology, v. 158, p. 1504-1512, 2012.

AYCICEK, H.; CAKIROGLU, S.; STEVENSON, T. H. Incidence of Staphylococcus aureus in ready-to-eat meals from military cafeterias in Ankara, Turkey. Food Control, v. 16 (6), p. 531-534, 2005.

BERGDOLL, M. S. Staphylococcal food poisoning. In D. O. Cliver (Ed.), Foodborne diseases (pp. 85-106). San Diego, CA: Academic Press. 1990.

BORBA, C. M. Avaliação físico-química de hambúrguer de carne bovina e de frango submetidos a diferentes processamentos térmicos. Porto Alegre (RS): Universidade Federal do Rio Grande do Sul. Trabalho de Conclusão do Curso de Nutrição. 2010.

BRASIL. Instrução Normativa $n^{\circ} 20$, de 31 de julho de 2000. Aprova os Regulamentos Técnicos de Identidade e Qualidade de Almôndega, de Apresuntado, de Fiambre, de Hambúrguer, de Kibe, de Presunto Cozido e de Presunto. Diário Oficial da União, Brasília, DF, 03 ago. 2000 .

BRASIL. Resolução RDC n. 12, de 02 de janeiro de 2001. Aprova o Regulamento Técnico sobre padrões microbiológicos para alimentos. Diário Oficial da União, Poder Executivo, Brasília, DF, 10 jan. 2001. 
BRYAN, F. L. Factors that contribute to outbreaks of foodborne disease. Journal of Food Protection, v. 41, p. 816-827, 1978.

BRYAN, F. L. Foodborne diseases in the United States associated with meat and poultry. Journal of Food Protection, v. 43, p. 140-150, 1980.

Center for Food Safety and Applied Nutrition. Foodborne pathogenic microorganisms and natural toxins. Center for Food Safety and Applied Nutrition, US Food and Drug Administration, Rockville, MD, USA. 1992.

ÇITAK, S.; VARLIK, Ö.; GÜNDOĞAN, N. Slime production and DNAse activity of Staphylococci isolated from raw milk. Journal of Food Safety, v. 23, p. 281-288, 2003.

CUNHA NETO, A.; SILVA, C. G. M.; STAMFORD, T. L. M. Staphylococcus enterotoxigênicos em alimentos in natura e processados no estado de Pernambuco, Brasil. Ciência e Tecnologia de Alimentos, v. 22, n. 3, p. 263-271, 2002.

DRAMOWSKI, A.; AUCAMP, M.; BEKKER, A.; MEHTAR, S. Infectious disease exposures and outbreaks at a South African neonatal unit with review of neonatal outbreak epidemiology in Africa. International Journal of Infectious Diseases, v. 57, p. 79-85, 2017.

ELDIRDIRI, S.; LEE, J.; JACK, A.; WRIGHT, A.; FINDLAY, A.; PHILLIPS, G. Outbreak of gentamicin-resistant, methicillin-susceptible Staphylococcus aureus on a neonatal unit. Journal of Hospital Infection, In Press, Accepted Manuscript. https://doi.org/10.1016/j.jhin.2017.11.006, 2017.

FAWZI, M. Investigation of bacterial food poisoning outbreaks in Alexandria, Egypt. Newsletter 62 (December): 8: FAO/WHO Collaborating Centre for Research and Training in Food Hygiene, Berlin, Germany. 1999.

FRANCO, B. D. G. M.; LANDGRAF, M. Microbiologia dos Alimentos. São Paulo: Atheneu, 1996.

GUNDOGAN, N.; CITAK, S.; YUCEL, N.; DEVREN, A. A note on the incidence and antibiotic resistance of Staphylococcus aureus isolated from meat and chicken samples. Meat Science, v. 69(4), p. 807-810, 2005.

HANASHIRO, A.; MORITA, M.; MATTÉ, G. R.; MATTÉ, M. H.; TORRES, E. A. F. S. Microbiological quality of selected street foods from a restricted area of São Paulo city, Brazil. Food control, v. 16, p. 439-444, 2005.

HOFFMAN, F. L. Fatores limitantes à proliferação de microorganismos em alimentos. Brasil Alimentos, v. 9, p. 23-30, 2001. 
HUNT, K. M.; PREUSS, J.; NISSAN, C.; DAVLIN, C. A.; WILLIAMS, J. E.; SHAFIL, B.; RICHARDSON, A. D.; MCGUIRE, M. K.; BODE, L.; MCGUIRE, M. A. Human milk oligosaccharides promote the growth of Staphylococci. Applied and Environmental Microbiology, v. 78, p. 4763-4770, 2012.

KANBAKAN, U.; ÇON, A. H.; AYAR, A. Determination of microbiological contamination sources during ice cream production in Denizli, Turkey. Food Control, v. 15, n. 6, p. 463470, 2004.

KATO, K.; ISHIWA, A. The role of carbohydrates in infection strategies of enteric pathogens. Tropical Medicine and Health, v. 43, p. 41-52, 2015.

PARDI, M. C.; SANTOS, I. F.; SOUZA, E. R.; PARDI, H. S. Ciência, higiene e tecnologia da carne. 2.ed. rev. ampl. Goiânia: UFG, v. 2. 2001.

PARRILLA-CERRILLO, M. C.; VAZQUEZ-CASTELLANOS， J. L.; SALDATECASTANEDA, E. O.; NAVA-FERNANDEZ, L. M. Outbreaks of food poisonings of microbial and parasitic origins. Salud Publica Mexicana, v. 35, p. 456-463, 1993.

QUEIROZ, Y. U.; DAUD, K. O.; SOARES, R. A. M.; SAMPAIO, G. R.; CAPRILES, V. D; TORRES, E. A. F. S. Desenvolvimento e avaliação das propriedades físicoquímicas de hambúrgueres com reduzidos teores de gordura e de colesterol. Revista Nacional da Carne, v. 338, p. 84-89, 2005.

RANUCCI, D.; MIRAGLIA, D.; BRANCIARI, R.; D'OVIDIO, V.; SEVERINI, M. Microbiological characteristics of hamburgers and raw pork sausages, and antibioticresistance of isolated bacteria. Veterinary Research Communications, v. 28(1), p. 269-272, 2004.

SANTOS JÚNIOR, L. C.; RIZZATTI, R.; BRUGNERA, A.; SCHIAVINI, T. J.; CAMPOS, E. F. M.; SCALCO NETO, J. F.; RODRIGUES, L. B.; DICKEL, E. L.; SANTOS, L. R. dos. Desenvolvimento de hambúrguer de carne de ovinos de descarte enriquecido com farinha de aveia. Ciência Animal Brasileira, v. 10, n. 4, p. 1128-1134, 2009.

SCHLEGELOVÁ, J.; NÁPRAVNÍKOVÁ, E.; DENDIS, M.; HORVÁTH, R.; BENEDÍK, J.; BABÁK, V.; KLÍMOVÁ, E.; NAVRÁTILOVÁ, P.; SUSTÁCKOVÁ, A. Beef carcass contamination in slaughterhouse and prevalence of resistance to antimicrobial drugs in isolates of selected microbial species. Meat Science, v. 66, n. 3, p. 557-565, 2004.

SHAHRAZ, F.; DADKHAH, H.; KHAKSAR, R.; MAHMOUDZADEH, M.; HOSSEINI, H.; KAMRAN, M.; BOURKE, P. Analysis of antibiotic resistance patterns and detection of mecA gene in Staphylococcus aureus isolated from packaged hamburguer. Meat Science, v. 90, p. 759-763, 2012. 
SILVA, S. E. R. Decomposição dos alimentos: ação dos micro-organismos. Monografia de Especialização em Educação: Métodos e Técnicas de Ensino. Universidade Tecnológica Federal do Paraná, Medianeira, 2012.

SILVA, W. P.; GRANDA, E. A. Estafilococos coagulase positiva: patógenos de importância em alimentos. Revista Higiene Alimentar, São Paulo, v. 18, n. 122, p. 32-40, jul. 2004.

SUZUKI, Y.; KUBOTA. H.; ONO, H. K.; KOBAYASHI, M.; MURAUCHI, K.; KATO, R.; HIRAI, A.; SADAMASU, K. Food poisoning outbreak in Tokyo, Japan caused by Staphylococcus argenteus. International Journal of Food Microbiology, v. 262, p. 31-37, 2017.

WITTE, R. S.; WITTE, J. S. Statistics. Fifth Edition.Harcourt Brace College Publishers, Orlando, U.S. A., 1997, 570p. 